\title{
Tactual picture identification by blind and sighted people: Effects of providing categorical information
}

\author{
MORTON A. HELLER, JEFFREY A. CALCATERRA, LYNNETTA L. BURSON, and LISA A. TYLER \\ Winston-Salem State University, Winston-Salem, North Carolina
}

\begin{abstract}
Four experiments examined the influence of categorical information and visual experience on the identification of tangible pictures, produced with a raised-line drawing kit. In Experiment 1, prior categorical information aided the accuracy and speed of picture identification. In a second experiment, categorical information helped subjects when given after the examination of each picture, but before any attempt at identification. The benefits of categorical information were also obtained in another group of subjects, when the superordinate categories were named at the start of the experiment. In a third experiment, a multiple-choice picture recognition task was used to eliminate the difficulty of naming from the picture-identification task. The multiple-choice data showed higher accuracy and shorter latencies when compared with identification tasks. A fourth experiment evaluated picture identification in blindfolded sighted, early, and late blind participants. Congenitally blind subjects showed lower performance than did the other groups, despite the availability of prior categorical information. The data were consistent with theories that assume that visual imagery aids tactual perception in naming raised line drawings. It was proposed that part of the difficulty in identification of raised line pictures may derive from problems in locating picture categories or names, and not merely in perception of the patterns.
\end{abstract}

There is no doubt that raised line drawings can communicate useful spatial information (Heller, 1989a, 1991; Heller \& Joyner, 1993; Heller \& Kennedy, 1990; Heller, Kennedy, \& Joyner, 1995; Kennedy, 1993; Millar, 1975,1991 ) even though the senses of vision and touch may differ in their ability to access pattern information that is dependent upon higher spatial frequencies (see Loomis, 1990). The study of tangible pictures has had a rather controversial history, with some researchers questioning the ability of blind people to make use of cues to perspective (e.g., Merry \& Merry, 1933) and interposition or fine detail (Revesz, 1950). In contrast, Heller (1989a) found that blind and sighted people were able to identify raised line drawings of common objects, with difficulty varying as a function of the picture and its characteristics. Furthermore, recognition performance was far better after subjects were given the set of labels that described the pictures. An interesting finding in the Heller (1989a) study was that the late blind had a clear advantage over the congenitally blind and the blindfolded sighted groups. Heller ascribed this superior performance to two factors. First, their experience with pictures is greater than that of the congenitally blind. Second, their tactual skills are greater than those of the sighted. However, visual experience did not appear necessary for pic-

Preparation of this report and some of the research were supported by NIH MBRS Grant 2 S06 RR-08040. Faith Heller provided helpful comments on an earlier version of this manuscript. Correspondence should be addressed to M. A. Heller, Psychology, Winston-Salem State University, Winston-Salem, NC 27110. ture identification, since the congenitally blind and blindfolded sighted participants performed at comparable levels.

An interesting theoretical perspective has been provided by Lederman and Klatzky (Klatzky \& Lederman, 1993; Lederman, Klatzky, Chataway, \& Summers, 1990; Loomis, Klatzky, \& Lederman, 1991). They argued that haptics is best suited for the perception of solids and tends to show lower performance when confronted with twodimensional configurations. Furthermore, the sense of touch seems to possess special capabilities for the detection of substance-related characteristics of objects, such as hardness, thermal properties, and texture (see Heller, $1989 b$ ). Lederman et al. (1990) reported poor performance when sighted and blind subjects attempted identification of tangible pictures, with much lower accuracy for the congenitally blind participants. These data led to the proposal that haptics may require the assistance of mediation by visual imagery when confronted with pictures. Earlier researchers have also stressed the role of visual imagery for haptics (Katz, 1989; Revesz, 1950). Katz (1989) thought that it was impossible to study haptics without the influence of visual experience and imagery in sighted subjects (p. 226). Furthermore, Katz stressed the advantages of touch for the detection of the microstructure of objects and their substance-related characteristics. Thus, he examined object recognition in congenitally blind individuals and assumed that they based their judgments on such characteristics as hardness or softness, thermal characteristics, and elasticity (Katz, 1989, p. 227). Revesz (1950, p. 156), who also assumed that 
sighted subjects visualize, asserted that "when we touch some common object, the tactile impression is always permeated with visual experiences." Revesz thought that the early blind were not able to become good sculptors, since they lacked visual imagery. Of course, it is difficult to know how important experience with pictures might be and whether or not performance in these tasks would be greatly improved by education (see Kennedy, 1993, pp. 95-126).

Thus, a number of researchers have questioned the nature of imagery in sighted and blind subjects when using touch. There is little doubt that sighted participants will tend to engage in visualization when attempting haptic tasks (Appelle, 1991; Appelle \& Gravetter, 1985; Heller, 1993; Heller \& Joyner, 1993; Revesz, 1950). It is not known, however, whether visualization is critical for the perception of some forms of pattern information. Arditi, Holtzman, and Kosslyn (1988) concluded that sighted and blind people differ in the nature of their imagery. They reported that imagery in congenitally blind people failed to follow the laws of perspective. Imagery in blind subjects, they claimed, did not include representations of decreasing image size with increased distance. Cornoldi and his colleagues have asserted that congenitally blind subjects process spatial information differently from the way in which sighted subjects process spatial information, with difficulty emerging when the tasks involved multiple interacting images (Cornoldi, Bertuccelli, Rocchi, \& Sbrana, 1993; Cornoldi, Cortesi, \& Preti, 1991). An alternative interpretation of this latter finding might ascribe apparent retention limitations in haptics to differential experience and somewhat slower processing in congenitally blind subjects. Heller and Kennedy (1990) found that congenitally blind subjects were able to perform as accurately as were sighted subjects in a Piagetian perspective-taking task, but they required much more time for their judgments (also see Lehtinen-Railo \& Juurmaa, 1994).

One generic theoretical difficulty in the interpretation of picture identification and naming tasks is that the experimental paradigm does not distinguish a naming failure from a deficiency in perceptual processes. Naming tactual pictures is dependent upon semantic memory, just as in vision (Snodgrass \& Vanderwart, 1980). It is conceivable that visual imagery may be important for access to labels and naming, rather than perception per se. Thus, one may see something adequately yet be unable to name it (Dretske, 1990). A young child may see a petsay, a dog or cat-perfectly well and know what it is, but the child may not know its name (also see Heller \& Schiff, 1991, p. 329). Alternatively, one may perceive a configuration properly, know its shape but not know what it is, and fail to provide the name of that object. On this interpretation of earlier research, subjects may know much about the shape in a tangible configuration but perhaps not know the category or the name. This is the viewpoint that is proposed in the present article. Moreover, prior research has shown that categorical informa- tion may be critical for tactile identification of numbers, letters, or geometric shapes (Heller, 1986; Heller, Nesbitt, \& Scrofano, 1991). Normal adults are very accurate when they vocally identify numerals, letters, or geometric shapes that are drawn on the skin of the palm or fingers (Critchley, 1953; Heller, 1980, 1986). However, performance suffers greatly if participants are denied categorical information or if they are not given prior knowledge about the orientation of the patterns. Indeed, failures in this skill are sometimes used as indicators of parietal damage (Critchley, 1953).

\section{THE PRESENT STUDY}

The present experiments were designed to separate the influence of naming from perceptual factors in identification of pictures with the sense of touch. Earlier research has yielded low tactual picture-identification scores, and it was considered possible that problems in naming could have contributed to these results. Experiment 1 examined the effect of categorical information on tactual picture naming. Identification accuracy was expected to increase with the provision of categorical information. Experiment 2 examined the effect of the succession of categorical information. One group of subjects received categorical information after touching each tangible picture but before an identification response. A second group was given the five picture categories at the beginning of the experiment. The purpose of Experiment 3 was to examine tactual picture identification without the problem of locating names or categories in semantic memory. Subjects searched for a target picture in a multiplechoice task. In Experiment 4, congenitally blind, adventitiously blind, and sighted controls attempted tactual picture identification. The purpose was to determine if visual experience contributed to performance when categorical information was provided. It was hypothesized that a major difficulty for touch may derive from problems in accessing labeling and categorical information, given raised line pictures.

\section{EXPERIMENT 1 \\ Effect of Categorical Information on Picture Identification}

In Experiment 1, the effect of prior categorical information on picture identification was examined. The purpose of this experiment was to study the influence of topdown processes on tangible picture identification. One group of subjects was given the name of the superordinate category of a picture prior to the presentation of each stimulus. A second group of subjects was denied this sort of information. Subject reports in earlier studies indicated that individuals were often aware of the configuration represented in a tangible display, yet they were unable to correctly name the picture (Heller,1989a; Kennedy, 1993). Some of this difficulty could have derived from problems in accessing categorical information. This anal- 
ysis assumes that subjects in earlier research understood the shape depicted in a tangible picture but were unable to decide upon the object that was represented and were also unable to name it. On this interpretation of the data of earlier reports, one might expect much higher identification scores for the group given prior categorical information.

\section{Method}

Subjects. The subjects were 20 undergraduates ( 4 males and 6 females in each of the two groups) recruited on the campus of Winston-Salem State University. Sighted subjects were blindfolded in this and subsequent experiments.

Stimuli and Apparatus. A raised line drawing kit was used to produce durable raised line drawings of pictures selected from the standardized set of depictions developed by Snodgrass and Vanderwart (1980) for use with vision. This drawing kit can be obtained from the Swedish agency for special education (SIH, Laromedel, Tomtebodavagen 11, 17164 Solna, Sweden). The Swedish drawing kit produces a tangible line when a ballpoint pen is drawn over the surface (see Heller, 1991). Five categories were selected (parts of the body, vehicles, fruits, kitchen utensils, and furniture). The pictures were chosen for reproducibility without loss of detail when enlarged and high ratings of name agreement (over $80 \%$ by Snodgrass \& Vanderwart, 1980). The drawings were between 7.5 and $10 \mathrm{~cm}$ in size. Since only side-view drawings were used in the experiment (with the exception of the bowl), some of the drawings were altered. Details were also omitted from some of the drawings to eliminate lines that indicated shading or shadow. The drawing of the bowl was included because earlier reports showed high identification scores for this pattern, despite the inclusion of foreshortening (Loomis et al., 1991). The drawings of the knife and spoon were traced from real objects, the drawing of the car and chair were taken from Kennedy $(1993$, pp. 68, 83), and the drawings of the table and the cherries were original. It should be noted that, after the experiment, sighted subjects were asked to look at all of the pictures they had touched. They visually identified them with the labels that were dominant in Snodgrass and Vanderwart. One subject, however, visually identified the cherries as "grapes," and another called them "apples." Two other anomalous visual responses included calling the table a "hurdle" or a "bridge." "Mouth" was accepted as a correct label for the lips, and this was a nondominant response in Snodgrass and Vanderwart (1980). Three drawings were made on each page with the raised line drawing kit (see Figure 1). The same random sequence was used for both groups in Experiment 1.

Design and Procedure. The experiment was a two-factor design; the provision of categorical information (or lack thereof) was a between-groups factor, and the superordinate category of drawing was a fully crossed, repeated measures variable (Winer, Brown, $\&$ Michels, 1991, p. 502). The participants were instructed to feel each of the outline drawings and name the object that the drawing represented. They were told that the pictures were objects that could be named. The subjects were timed but were told to try for accuracy. They were told they could use either or both hands, as they wished. They were given as much time as needed to identify each of the drawings. The subjects were blindfolded throughout. The blindfolds were the older models produced by Lafayette Instruments and were completely effective in blocking vision. These blindfolds used two layers of plastic for the obstruction of light. Subjects in the categorization condition were told the appropriate superordinate category name (furniture, fruit, vehicles, parts of the human body, or kitchen utensils) prior to the presentation of each of the drawings. No feedback was given, but indecisive subjects were asked to clarify their answers and guess if uncertain. The subjects were timed on each picture with a stopwatch.
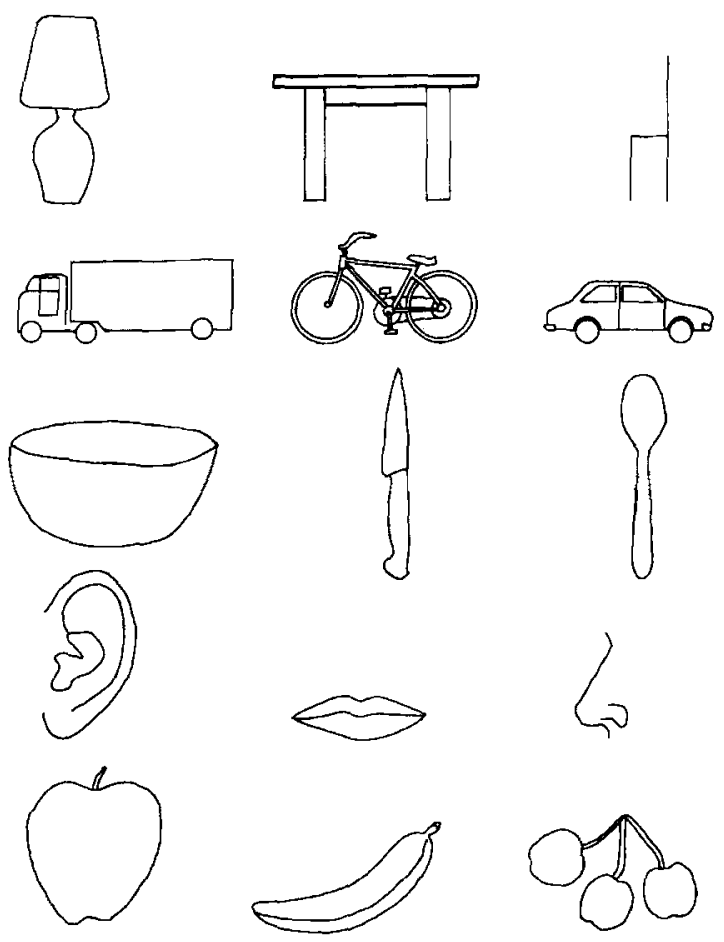

Figure 1. The drawings (drawn to scale) used in this study. The superordinate categories and stimuli included: Furniture lamp, table, chair; Vehicles - truck, bicycle, car; Kitchen Utensils - bowl, knife, spoon; Parts of the Body-ear, lips, nose; Fruit-apple, banana, cherries.

\section{Results and Discussion}

Identification accuracy was high when the subjects were given information about a picture's categorical status prior to its examination ( $M=63.3 \%$ correct $)$, but it was much lower in the no-information group $(M=24.7 \%$ correct). The mean number correct for the group given categorical information was 9.5 out of 15 pictures $(S D=$ 2.2 ); mean number correct for the group without this prior information was only $3.7(S D=1.9)$. The effect of categorical information was highly significant $[t(18)=6.3$, $p<.01]$. Table 1 shows percent correct and latencies for the different pictures. An analysis of variance (ANOVA) was performed on the accuracy data, with picture category as a within-groups variable (see Table 2 ). The provision of categorical information significantly increased the accuracy of tangible picture identification $[F(1,18)=$ $39.5, p<.001]$, and the ease of picture identification was also influenced by category membership $[F(4,72)=3.5$, $p=.011]$. However, the interaction was nonsignificant $[F(4,72)=1.3, p>.05]$. Performance was best for fruit, kitchen utensils, and furniture.

A second ANOVA was performed on response time (RT) for each picture, and it showed that the subjects were significantly faster when given categorical information $(M=30.4 \mathrm{sec})$ than when they were given no categorical information $(M=52.8 \mathrm{sec})[F(1,18)=18.8, p<.001]$. Mean RT varied with the picture $[F(14,252)=5.6, p<$ 
Table 1

Percent Correct, Mean Identification Time (in Seconds), and Standard Deviation of Identification Time (in Seconds) as a Function of Picture and Categorical Information in Experiment 1

\begin{tabular}{|c|c|c|c|c|c|c|}
\hline \multirow[b]{2}{*}{ Picture } & \multicolumn{3}{|c|}{$\begin{array}{l}\text { No Categorical } \\
\text { Information }\end{array}$} & \multicolumn{3}{|c|}{$\begin{array}{c}\text { Categorical Information } \\
\text { Given }\end{array}$} \\
\hline & $\begin{array}{l}\text { Percent } \\
\text { Correct } \\
\end{array}$ & Time & $S D$ & $\begin{array}{l}\text { Percent } \\
\text { Correct }\end{array}$ & Time & $S D$ \\
\hline Chair & 60 & 24.7 & 9.2 & 100 & 21.2 & 16.8 \\
\hline Lamp & 10 & 42.5 & 20.5 & 30 & 57.5 & 29.6 \\
\hline Table & 50 & 63.5 & 17.5 & 80 & 32.6 & 27.9 \\
\hline Bicycle & 10 & 62.7 & 33.1 & 30 & 44.8 & 22.4 \\
\hline Car & 20 & 58.3 & 29.4 & 70 & 26.6 & 17.4 \\
\hline Truck & 10 & 63.5 & 44.1 & 60 & 36.5 & 21.9 \\
\hline Bowl & 30 & 37.8 & 14.4 & 60 & 36.5 & 37.8 \\
\hline Knife & 0 & 73.8 & 28.7 & 70 & 28.0 & 11.6 \\
\hline Spoon & 10 & 34.7 & 14.7 & 90 & 14.6 & 8.3 \\
\hline Ear & 10 & 74.6 & 45.0 & 50 & 42.7 & 37.7 \\
\hline Lips & 40 & 50.4 & 28.0 & 50 & 26.0 & 18.5 \\
\hline Nose & 10 & 58.7 & 25.5 & 40 & 33.4 & 21.1 \\
\hline Apple & 40 & 29.8 & 23.4 & 90 & 13.9 & 6.6 \\
\hline Banana & 60 & 47.2 & 19.9 & 100 & 10.6 & 6.8 \\
\hline Cherries & 10 & 70.4 & 26.1 & 30 & 30.9 & 15.9 \\
\hline
\end{tabular}

$.001]$, and picture type interacted with prior categorical information $[F(14,252)=2.5, p<.01]$. Thus, prior categorical information aided some pictures more than others. In addition, an ANOVA was performed on latency information, with item category as a within-subjects variable. Picture category influenced identification times $[F(4,72)=4.3, p<.01]$, but the interaction between prior information and category membership was nonsignificant $[F(4,72)=2.3, p>.05]$. Response latencies were especially short for the pictures of fruit and kitchen utensils when prior categorical information was provided (see Table 2).
A major component of the difficulty that participants experience when feeling raised line pictures may derive from problems in accessing semantic information - that is, category information and names. This is indicated by the great improvement shown when categorical information was given. Note that both accuracy $(63.3 \%$ correct overall) and speed were aided by prior categorical information. Thus, subjects are often precise in their haptic perception of two-dimensional configurations (see Heller \& Joyner, 1993), but they may still find themselves unable to provide the name of a tangible picture. These data do not suggest that sensory factors have little or no effect on the identification of tangible pictures. Some of the identification errors are explicable in terms of a failure to resolve fine detail. For example, 6 of the subjects in the group given categorical information answered "grapes" for the picture of the cherries. These participants may have failed to notice the slight shape difference between the two types of fruit, as well as differences in the configuration of the stems. Thus, it is likely that subjects that called them "apples" also probably failed to notice differences in the configuration of the stems. In addition, the bicycle was called a "motorcycle" by 2 subjects. ${ }^{1}$ Note that most of the errors were that of commission, rather than omission, but the errors changed as a function of prior categorical information. The subjects rarely failed to guess at a picture name; however, in the prior-information group, they invariably gave a response that was consistent with the category name.

Performance overall was generally comparable to that in earlier studies, despite the use of different pictures. Of course, accuracy was much higher in the present experiment for the group given categorical information $(63.3 \%$ correct). Lederman et al. (1990) reported 33\% correct,

Table 2

Percent Correct, Mean Number Correct, Mean Identification Time (in Seconds), and Standard Deviation as a Function of Category and Prior Categorical Information in Experiment 1

\begin{tabular}{|c|c|c|c|c|c|c|}
\hline \multirow[b]{2}{*}{ Category } & \multicolumn{3}{|c|}{$\begin{array}{l}\text { No Categorical } \\
\text { Information }\end{array}$} & \multicolumn{3}{|c|}{$\begin{array}{c}\text { Categorical Information } \\
\text { Given }\end{array}$} \\
\hline & $\begin{array}{l}\text { Percent } \\
\text { Correct }\end{array}$ & $\begin{array}{c}\text { Mean No. } \\
\text { Correct }\end{array}$ & Time & $\begin{array}{l}\text { Percent } \\
\text { Correct }\end{array}$ & $\begin{array}{c}\text { Mean No. } \\
\text { Correct }\end{array}$ & Time \\
\hline \multicolumn{7}{|l|}{ Furniture } \\
\hline$M$ & 40.0 & 1.2 & 43.5 & 70.0 & 2.1 & 37.1 \\
\hline$S D$ & 26.3 & 0.8 & 8.4 & 18.9 & 0.6 & 21.5 \\
\hline \multicolumn{7}{|l|}{ Vehicles } \\
\hline$M$ & 13.3 & 0.4 & 61.5 & 53.3 & 1.6 & 35.9 \\
\hline$S D$ & 23.3 & 0.7 & 24.5 & 28.1 & 0.8 & 16.3 \\
\hline \multicolumn{7}{|c|}{ Kitchen utensils } \\
\hline$M$ & 13.3 & 0.4 & 48.8 & 73.3 & 2.2 & 26.4 \\
\hline$S D$ & 17.2 & 0.5 & 11.3 & 26.3 & 0.8 & 11.7 \\
\hline \multicolumn{7}{|l|}{ Body parts } \\
\hline$M$ & 20.0 & 0.6 & 61.2 & 46.7 & 1.4 & 34.0 \\
\hline$S D$ & 32.2 & 1.0 & 23.6 & 32.2 & 1.0 & 20.9 \\
\hline \multicolumn{7}{|l|}{ Fruit } \\
\hline$M$ & 36.7 & 1.1 & 49.1 & 73.3 & 2.2 & 18.5 \\
\hline$S D$ & 36.7 & 1.1 & 13.5 & 21.1 & 0.6 & 7.4 \\
\hline
\end{tabular}

Note-There were three pictures in each category. 
but performance was only $24.7 \%$ correct in the group denied categorical information in the present experiment. While scores were slightly lower for the group that did not receive categorical information, latencies were much shorter than described in earlier published reports. Note that mean overall RT was $52.8 \mathrm{sec}$ in the no-information group, whereas it was much faster when participants were given prior categorical knowledge ( $M=30.4 \mathrm{sec})$. Categorical information had no effect on RT for a few pictures that were already easy for the observers (e.g., the chair, see Table 1). Some pictures were identified more rapidly, and some were much more difficult; body parts and vehicles were most difficult.

It was not surprising that the simpler pictures sometimes yielded the greatest accuracy and shortest RTs (banana, chair, apple, spoon). However, some simple pictures were not very easy. Identification of the nose was difficult, perhaps because it was presented out of context. The lower accuracy for stimuli in general, which was reported in an earlier article (12.9\% for blindfolded sighted participants; Heller, 1989a), was probably due to the use of different stimuli. The present data on the effects of prior categorical information are consistent with an informal report by Kennedy $(1993$, p. 83) on tactual picture recognition in blind children. After initial naming failures, Kennedy then cued picture identification with "hints," consisting of superordinate categories. These prompts aided performance.

It should be noted that Heller (1989a) found that subjects performed better in a picture-naming task after they were told the set of labels that described the pictures they first felt without this information. Thus, providing the set of names aided picture identification for sighted, lateblind, and congenitally blind participants. The earlier (Heller, 1989a) experiment did not, however, examine the effect of categorical information on tangible picture identification. Thus, the results of the present experiment showed that naming failures often involved an inability on the part of subjects to identify the general category of items in a tangible picture. In addition, performance was unusually low when sighted and congenitally blind subjects (Heller, 1989a) initially attempted picture naming, and this means that the results of that study should be interpreted with caution. However, the present results lend additional support to the idea that higher order cognitive variables necessarily intervene in tangible picture identification.

\section{EXPERIMENT 2 \\ Categorical Information Given After Each Trial or at the Beginning of the Experiment}

Categorical information clearly helped the subjects as they attempted identification of tangible pictures. This suggests that the subjects may have been aware of the form represented in a picture, but they were unable to name the tangible depiction. A reviewer pointed out that prior categorical information could have altered the nature of tactual exploration. Thus, the subjects may have searched for features that characterize a class of objects. For ex- ample, if one were to tell subjects that a picture was that of a type of vehicle, subjects know that many vehicles have wheels and then they would search for round shapes on the bottom of the picture. With this interpretation of the results of Experiment 1, the effect of categorical information might be partly attentional or exploratorythat is, perceptual. One way to answer the question of whether categorical information aids perceptual uptake or operates at a higher level (e.g., via categorizing or naming) would be to provide categorical information after the presentation of each picture but before subjects attempted naming.

In addition, it is possible that the subjects in Experiment 1 became aware of the range of categories because of repeated exposure to category names. It was not possible to determine this from a statistical analysis of the data, because all subjects experienced a constant, random sequence of the pictures. While performance was lower for the last 7 pictures, the design confounded repeated presentation of picture category with difficulty of the individual items. However, the influence of knowledge of the range of categories can be studied by including a group of subjects that is given the five superordinate categories at the start of the experiment.

Therefore, one group of subjects in Experiment 2 was given categorical information after each picture was presented but before attempting identification of the picture. A second group of subjects was told the names of the superordinate categories at the start of the experiment, but the category names were not linked to individual pictures. If the effect of categorical information were mainly perceptual, one would not expect that categorical information would help subjects when given after the pictures. Moreover, perceptual explanations would predict much lower performance for both of these groups than that obtained in Experiment 1. If categorical information is picked up by subjects as a consequence of repeated exposure to picture categories, one would expect that providing category information at the start of the experiment should help identification. Thus, performance was expected to be better for the subjects in Experiment 2 than for the subjects in Experiment 1 who were denied prior categorical information. Perceptual explanations of the categorical information effect should lead to the expectation that performance should be much lower if categorical information were given at the beginning of the experiment rather than if category names were presented prior to each picture. Linking presentation of category information to individual pictures would be more likely to aid perceptual uptake.

\section{Method}

Subjects. The subjects were 20 undergraduates $(5$ males and 5 females in each of two groups) recruited on the campus of Winston-Salem State University. None of the subjects served in Experiment 1 .

Stimuli. The stimuli were the same as those used in Experiment 1, but a fresh, duplicate set of tangible drawings was prepared.

Design and Procedure. The experiment was a two-factor design, with succession of the presentation of categorical information 
Table 3

Percent Correct, Mean Identification Time (in Seconds), and Standard Deviation of Identification Time (in Seconds) as a Function of Picture and Succession of Categorical Information (at the Start of the Experiment or After Each Picture) in Experiment 2

\begin{tabular}{lccccccc}
\hline & \multicolumn{2}{c}{$\begin{array}{c}\text { Information Given } \\
\text { After Each Picture }\end{array}$} & & \multicolumn{2}{c}{$\begin{array}{c}\text { Information Given at } \\
\text { Beginning of Experiment }\end{array}$} \\
\cline { 2 - 4 } Picture & $\begin{array}{c}\text { Percent } \\
\text { Correct }\end{array}$ & Time & $S D$ & $\begin{array}{c}\text { Percent } \\
\text { Correct }\end{array}$ & Time & $S D$ \\
\hline Chair & 100 & 22.9 & 11.2 & 80 & 39.3 & 29.4 \\
Lamp & 30 & 57.4 & 35.6 & 20 & 103.9 & 53.6 \\
Table & 90 & 71.5 & 38.5 & 70 & 85.1 & 42.7 \\
Bicycle & 20 & 78.1 & 74.6 & 20 & 80.7 & 54.5 \\
Car & 60 & 59.1 & 49.2 & 60 & 84.3 & 77.0 \\
Truck & 60 & 63.5 & 50.3 & 30 & 98.2 & 62.6 \\
Bowl & 30 & 40.0 & 21.5 & 30 & 55.4 & 35.5 \\
Knife & 30 & 49.3 & 26.1 & 70 & 68.4 & 45.6 \\
Spoon & 100 & 35.3 & 24.0 & 80 & 32.4 & 21.7 \\
Ear & 60 & 65.2 & 58.1 & 70 & 86.9 & 87.5 \\
Lips & 30 & 40.5 & 29.6 & 30 & 43.7 & 28.7 \\
Nose & 20 & 56.0 & 56.6 & 30 & 84.5 & 45.4 \\
Apple & 90 & 22.3 & 11.2 & 70 & 63.1 & 65.5 \\
Banana & 100 & 29.4 & 11.4 & 100 & 39.2 & 40.0 \\
Cherries & 50 & 64.6 & 38.8 & 30 & 93.4 & 80.8 \\
\hline
\end{tabular}

(at start of experiment or after each picture) as a between-groups variable; repeated measures were taken on picture category. In most other respects, the procedure was the same as that in Experiment 1 . For subjects given categorical information at the start of the experiment, the instructions were that the pictures would be drawn from the five named categories, but no other information was given, nor was feedback provided. The subjects in the other group were given categorical information after the presentation of each picture. They were told that they should examine the tangible pictures until they thought they had a good idea of the configuration, and then the picture would be taken away. Subsequently, they were told the category name corresponding to the picture and were then told to identify the picture. The subjects were not allowed to touch the pictures again after they were given the category name. The subjects given information after each picture were timed until they indicated that they were satisfied that they had an understanding of the configuration represented in each display. Thus, they were tined on the amount of time that they touched each picture. Feedback was not given, and all subjects were blindfolded throughout.

\section{Results and Discussion}

Categorical information aided the subjects in both groups, and performance was comparable to that of the group that received prior categorical information in Experiment 1 (see Tables 3 and 4). Mean number correct was similar when picture category was named after each picture $(M=8.7, S D=2.8$; mean percent correct $=58)$ and when the category names were given at the start of the experiment $(M=7.9, S D=1.6$; mean percent correct $=52.7)$. An ANOVA on number correct showed that the effect of picture category was highly significant $[F(4,72)=6.2, p<.001]$. The effect of succession of categorical information was nonsignificant, as was the interaction (both $F \mathbf{s}<1$ ).

A second ANOVA on time scores showed that the effect of succession of categorical information failed to reach significance $[F(1,18)=2.97, p>.10]$; the effect of picture category was significant $[F(4,72)=3.4, p<$ $.05]$, but the interaction was nonsignificant $(F<1)$. A separate analysis, with picture as a within-subject variable, showed a highly significant effect of picture on time scores $[F(14,252)=4.4, p<.001]$. Although some pictures were named faster than others, this did not depend upon the succession of categorical information.

It seems unlikely that the effect of categorical information could be explained solely in terms of changes in exploratory strategies, since performance was also helped by naming the categories after the presentation of each picture. The data of Experiment 1 were reanalyzed to include

Table 4

Percent Correct, Mean Number Correct, Mean Time (in Seconds), and Standard Deviation as a Function of Category and Succession of Categorical Information (at the Start of the Experiment or After Each Picture) in Experiment 2

\begin{tabular}{|c|c|c|c|c|c|c|}
\hline \multirow[b]{2}{*}{ Category } & \multicolumn{3}{|c|}{$\begin{array}{l}\text { Information Given } \\
\text { After Each Picture }\end{array}$} & \multicolumn{3}{|c|}{$\begin{array}{c}\text { Information Given at } \\
\text { Beginning of Experiment }\end{array}$} \\
\hline & $\begin{array}{l}\text { Percent } \\
\text { Correct }\end{array}$ & $\begin{array}{c}\text { Mean No, } \\
\text { Correct }\end{array}$ & Time & $\begin{array}{l}\text { Percent } \\
\text { Correct }\end{array}$ & $\begin{array}{c}\text { Mean No. } \\
\text { Correct }\end{array}$ & Time \\
\hline \multicolumn{7}{|l|}{ Furniture } \\
\hline$M$ & 73.3 & 2.2 & 50.6 & 56.7 & 1.7 & 76.1 \\
\hline$S D$ & 21.1 & 0.6 & 25.3 & 16.1 & 0.5 & 31.0 \\
\hline \multicolumn{7}{|l|}{ Vehicles } \\
\hline$M$ & 46.7 & 1.4 & 66.9 & 36.7 & 1.1 & 87.8 \\
\hline$S D$ & 28.1 & 0.8 & 44.7 & 36.7 & 1.1 & 46.4 \\
\hline \multicolumn{7}{|c|}{ Kitchen utensils } \\
\hline$M$ & 53.3 & 1.6 & 41.6 & 60.0 & 1.8 & 52.1 \\
\hline$S D$ & 17.2 & 0.5 & 20.3 & 21.1 & 0.6 & 14.5 \\
\hline \multicolumn{7}{|l|}{ Body parts } \\
\hline$\dot{M}$ & 36.7 & I. I & 53.9 & 43.3 & 1.3 & 71.7 \\
\hline$S D$ & 39.9 & 1.2 & 45.8 & 41.7 & 1.3 & 47.2 \\
\hline \multicolumn{7}{|l|}{ Fruit } \\
\hline$M$ & 80.0 & 2.4 & 38.8 & 66.7 & 2.0 & 65.2 \\
\hline$S D$ & 17.2 & 0.5 & 17.4 & 22.2 & 0.7 & 48.5 \\
\hline
\end{tabular}


the accuracy and latency data from Experiment 2. Thus, one can consider the two experiments as one, with independent groups of subjects getting categorical information prior to each picture, after each picture, at the start of the experiment, or not at all. Of course, repeated measures were taken on picture category. As expected, categorical information significantly affected the accuracy of picture identification $[F(3,36)=14.1, p<.001]$, the effect of picture category was significant $[F(4,144)=9.4$, $p<.001]$, but the interaction was nonsignificant $(F<1)$. A Newman-Keuls test on the means of the groups showed that the no-information group had significantly lower scores than did all of the groups in the information conditions $(p<.01)$, but no other comparison was significant. This indicates that the succession of categorical information did not alter the accuracy of picture identification-a result that is counter to the idea that bottomup perceptual processes can fully explain the effect of categorical information.

A further ANOVA on time scores for the four information groups also showed a highly significant effect of categorical information $[F(3,36)=6.6, p<.01]$, a significant effect of picture category $[F(4,144)=6.1, p<$ $.01]$, and a nonsignificant interaction $(F<1)$. A NewmanKeuls test on the means for the four information groups showed that giving categorical information prior to each picture yielded significantly faster latencies than for all other groups $(p<.05)$. In addition, the subjects were significantly faster when the category name was given after each picture than when the five categories were given at the start of the experiment $(p<.05)$. Perhaps, giving the categories at the start of the experiment leads to more exhaustive tactual search. Alternatively, subjects may mentally consider more alternative names when making identifications in this condition. Moreover, this indicates that succession of categorical information can speed up or slow down the judgmental process.

The overall data indicate that succession of categorical information had little effect on accuracy. However, it is still possible that exploration strategies might be altered as a function of categorical information. A hint of this derived from an examination of performance on individual pictures. The subjects did very poorly on the picture of the knife in the no-information group ( 0 correct) and when the category name followed the presentation of the picture ( 3 correct). Performance was better when the subjects were told the categories at the start of the experiment or prior to each picture ( 7 correct for both groups). Thus, the subjects may have expected a pointy object and looked for this in the tangible pictures. This was not apparent in the behavior or scores of the groups denied prior information.

\section{EXPERIMENT 3 Multiple-Choice Recognition Task}

The results of Experiments 1 and 2 showed that categorical information aided picture identification in a nam- ing task. These data suggest that a major part of the difficulty with haptic picture identification may involve reduced access to categories and picture names or labels, perhaps due to lack of familiarity with the task. Performance was improved, though far from perfect, in the categorical information conditions. Consequently, Experiment 3 was designed to remove the label and memory problem from the picture-recognition task. On each trial, the subjects were given 3 categorically related pictures and asked to find a named target picture. One group of subjects was given prior categorical information about the 3 pictures on each choice card; the other group of subjects was merely directed to find a named target item. This experiment pitted name information against nameplus-category information. The subjects were expected to perform better when given both sorts of information prior to each picture. If naming and identification of category were a significant part of the difficulty that subjects experience when first feeling unfamiliar tactual pictures, one might expect much higher performance than that in Experiments 1 and 2.

\section{Method}

Subjects. There were 20 sighted subjects $(4$ males and 6 females in each of two groups) recruited on the campus of WinstonSalem State University. None of the subjects served in Experiments 1 and 2 .

Stimuli. The 15 tangible pictures were identical to those in Experiments 1 and 2 . However, the 3 pictures within each category were presented on the same stimulus sheet.

Design and Procedure. The experiment was a two-factor design, with the between-groups factor being prior categorical information; repeated measures were taken on picture category. As in Experiment 1, the subjects had 15 trials, with an attempt to identify the 15 raised line pictures. On each trial, blindfolded subjects were told they would have 3 pictures on each page. They were told to feel the 3 pictures and then try to find the target picture. In the group given prior categorical information, the participants were told the name of the major category that contained all 3 pictures and were then told they should find the target picture. The subjects were told they would feel 3 pictures of, for example, fruit and should find the apple. The three choices were the same when the cherries and banana were the targets and the same for each picture within a categorical triad, such that each picture was presented three times. A single random sequence of pictures was used, but half of the subjects in each condition used the reverse sequence and started with the last item.

Feedback was not given. Each blindfolded participant was timed on the sets of pictures from the first contact with the first picture until he/she identified the target item. The subjects were informed that they would be timed, but they were told to try for accuracy. The subjects were told the location of the 3 pictures on each of the pages, prior to tactual examination, and were required to feel all 3 pictures before answering.

\section{Results and Discussion}

Performance was much higher in the multiple-choice recognition task than in the identification tasks of Experiments 1 and 2. Furthermore, performance was very good, and both groups showed similar accuracy. The mean number correct for the categorical information group was $13.3(S D=1.7)$; the mean number correct for 
Table 5

Percent Correct, Mean Identification Time (in Seconds), and Standard Deviation of Identification Time (in Seconds) as a Function of Picture and Categorical Information in the Multiple-Choice Task in Experiment 3

\begin{tabular}{|c|c|c|c|c|c|c|}
\hline \multirow[b]{2}{*}{ Picture } & \multicolumn{3}{|c|}{$\begin{array}{l}\text { No Categorical } \\
\text { Information }\end{array}$} & \multicolumn{3}{|c|}{$\begin{array}{c}\text { Categorical Information } \\
\text { Given }\end{array}$} \\
\hline & $\begin{array}{l}\text { Percent } \\
\text { Correct }\end{array}$ & Time & $S D$ & $\begin{array}{l}\text { Percent } \\
\text { Correct }\end{array}$ & Time & $S D$ \\
\hline Chair & 40 & 68.4 & 57.8 & 80 & 63.0 & 49.4 \\
\hline Lamp & 100 & 43.0 & 23.3 & 80 & 46.5 & 29.4 \\
\hline Table & 100 & 45.1 & 29.6 & 100 & 43.0 & 33.5 \\
\hline Bicycle & 70 & 57.5 & 30.3 & 60 & 70.9 & 52.5 \\
\hline Car & 40 & 56.3 & 32.9 & 50 & 81.3 & 57.3 \\
\hline Truck & 70 & 56.7 & 32.0 & 80 & 77.3 & 68.0 \\
\hline Bowl & 100 & 32.5 & 14.5 & 100 & 27.8 & 11.7 \\
\hline Knife & 90 & 48.7 & 30.7 & 100 & 27.8 & 19.5 \\
\hline Spoon & 100 & 34.5 & 31.3 & 100 & 29.6 & 16.5 \\
\hline Ear & 80 & 36.9 & 11.4 & 100 & 38.4 & 20.2 \\
\hline Lips & 100 & 31.0 & 19.8 & 100 & 29.3 & 29.3 \\
\hline Nose & 70 & 60.7 & 35.8 & 90 & 31.7 & 18.5 \\
\hline Apple & 100 & 29.4 & 13.9 & 90 & 23.3 & 13.5 \\
\hline Banana & 100 & 28.2 & 17.7 & 100 & 28.6 & 24.3 \\
\hline Cherries & 100 & 33.1 & 18.8 & 100 & 28.5 & 18.2 \\
\hline
\end{tabular}

the no-information group was $12.6(S D=1.5)$. Recognition accuracy was far higher when access to semantic memory was not a problem in the information group $(88.7 \%$ correct) and in the no-information group (84\% correct). This suggests that the lack of access to semantic information is a major source of difficulty in naming some tactual pictures. An ANOVA on number correct showed a significant effect of picture category $[F(4,72)=$ $12.8, p<.01]$, but the other effects were nonsignificant $(F \mathrm{~S}<1)$.

A second ANOVA was performed on RT, with a significant effect of category of picture $[F(4,72)=13.2$, $p<.01]$, but the effect of categorical information was nonsignificant $(F<1)$. The interaction failed to reach significance $[F(4,72)=2.1, p>.05]$.

Tables 5 and 6 show performance for the individual pictures and categories. It is clear that performance was very good and that many of the errors occurred with the pictures of vehicles. If one were to exclude those particular pictures from consideration, recognition accuracy would be excellent. The time scores include the time it took the subjects to search through 3 pictures for a target. Thus, the subjects performed much faster per picture in this task than when they were asked to name individual pictures. It is possible that performance suffers in the vehicle category because these pictures are complex and include a great deal of fine detail. This is one obvious case where the lower spatial acuity of the fingertip can be problematic for information pickup by touch (Loomis, 1990).

It should be noted that Experiment 3 used repeated presentations of pictures. Thus, it could be argued that this confounded a change in procedure from Experiments 1 and 2 with changes in stimulus familiarity. However, RTs were so short that the subjects could not have engaged in exhaustive search of tactual features when examining each trio of drawings on a page. Furthermore, if one were able to ascribe the increase in performance to familiarity alone, one is then justified in making an appropriate related argument that low performance in tactual picture identification may often be a consequence of lack of familiarity with raised line pictures. In addition, it is important to note that most of the stimuli in these experiments were visually normed, and this may have altered the results of the experiments. This later point will be discussed further, elsewhere in the article. It is impossible to exclude the possibility, of course, that prior

Table 6

Percent Correct, Mean Number Correct, Mean Identification Time (in Seconds), and Standard Deviation as a Function of Category and Prior Categorical In formation in the Multiple-Choice Task in Experiment 3

\begin{tabular}{|c|c|c|c|c|c|c|}
\hline \multirow[b]{2}{*}{ Category } & \multicolumn{3}{|c|}{$\begin{array}{l}\text { No Categorical } \\
\text { Information }\end{array}$} & \multicolumn{3}{|c|}{$\begin{array}{c}\text { Categorical Information } \\
\text { Given }\end{array}$} \\
\hline & $\begin{array}{l}\text { Percent } \\
\text { Correct }\end{array}$ & $\begin{array}{l}\text { Mean No. } \\
\text { Correct }\end{array}$ & Time & $\begin{array}{l}\text { Percent } \\
\text { Correct }\end{array}$ & $\begin{array}{c}\text { Mean No. } \\
\text { Correct }\end{array}$ & Time \\
\hline \multicolumn{7}{|l|}{ Furniture } \\
\hline$M$ & 80.0 & 2.4 & 52.2 & 86.7 & 2.6 & 50.8 \\
\hline$S D$ & 17.2 & 0.5 & 26.2 & 23.3 & 0.7 & 26.9 \\
\hline \multicolumn{7}{|l|}{ Vehicles } \\
\hline$M$ & 60.0 & 1.8 & 56.8 & 63.3 & 1.9 & 76.5 \\
\hline$S D$ & 34.4 & 1.0 & 28.2 & 36.7 & 1.1 & 54.5 \\
\hline \multicolumn{7}{|c|}{ Kitchen utensils } \\
\hline$M$ & 96.7 & 2.9 & 38.6 & 100.0 & 3.0 & 28.4 \\
\hline$S D$ & 10.5 & 0.3 & 22.2 & 0 & 0 & 9.2 \\
\hline \multicolumn{7}{|l|}{ Body parts } \\
\hline$M$ & 83.3 & 2.5 & 42.9 & 96.7 & 2.9 & 33.1 \\
\hline$S D$ & 17.6 & 0.5 & 17.5 & 10.5 & 0.3 & 14.1 \\
\hline \multicolumn{7}{|l|}{ Fruit } \\
\hline$M$ & 100.0 & 3.0 & 30.2 & 96.7 & 2.9 & 26.8 \\
\hline$S D$ & 0 & 0 & 11.2 & 10.5 & 0.3 & 12.5 \\
\hline
\end{tabular}


knowledge about picture category or picture name altered the nature of tactual exploration. Thus, if a subject is given the name of, say, the spoon, the subject may search for a rounded or oval contour. For this subject, the provision of categorical information is redundant and giving names and categories may independently lead to more efficient tactual exploration of the displays. However, the results of Experiment 2 showed that this explanation cannot fully explain the benefits of categorical information.

\section{EXPERIMENT 4 \\ Tactual Picture Identification in Sighted, Congenitally Blind, and Late Blind People}

The purpose of Experiment 4 was to evaluate the contribution of visual experience to tactual picture identification. This experiment compared the performance of blindfolded sighted, late blind, and congenitally blind subjects in a picture-identification task. In this task, all participants were given prior information about the categorical status of each of the tangible pictures. If visual imagery were necessary for mediation of haptic representations of two-dimensional arrays, one might expect that sighted subjects would show higher levels of performance than would congenitally blind participants. However, since some prior research (Heller, 1989a) has shown similar performance for these two groups, it was considered possible that congenitally blind participants would perform at a level comparable to the blindfolded sighted individuals. Unfortunately, the low initial performance levels of the blindfolded sighted and of the blind participants in the Heller (1989a) experiment may have obscured any possible differences between the groups due to a floor effect. It was expected that performance levels would be much higher in the present experiment, since the subjects were always given prior knowledge about the categorical status of the tangible pictures.

\section{Method}

Subjects. The 10 sighted subjects ( 5 males and 5 females; mean age $=32.6$ years) were blindfolded throughout; none served in the earlier experiments. There were 10 congenitally blind subjects (mean age of loss of sight $=0.05$ years) and 10 late blind subjects (mean age of loss of sight $=19.65$ years, median age of loss of sight $=$ 12.5; see Table 7). Only 2 of the congenitally blind subjects had some vision during the first 3 months of life; the others were blind at birth or when removed from incubators (in the case of the retrolental fibroplasia subjects). Most of the blind participants were employees at Industries of the Blind workshops in Winston-Salem and Greensboro, but some were recruited from the wider community in Winston-Salem. Two of the blind participants had graduate degrees and were vocational counselors at North Carolina Services for the Blind ( 1 congenitally blind, 1 late blind). The majority of the blind subjects were "new" to experiments on tactual picture identification. However, 4 of the late blind and 4 of the congenitally blind subjects participated in an earlier experiment on picture identification (Heller, 1989a). None of the blind participants had more than minimal light perception.

Stimuli. The tangible pictures were identical to those in Experiment 3-that is, the 3 pictures within each category were presented on the same stimulus sheet. The pictures were presented in a random sequence.

Design and Procedure. The experiment was an independent groups design, with visual status as the major variable (sighted, late blind, congenitally blind). Of course, it is possible to consider this experiment as a two-factor design, with picture category as a crossed within-groups variable. The procedure was similar to that in Experiment 1 . The subjects were presented with a tangible picture, but they were always first given information about the picture's categorical status. The subjects were told where on each stimulus sheet to explore and named one picture on each trial. Thus, the subjects were told to explore on the left, right, or in the middle, as appropriate. The blind and blindfolded subjects had no difficulty following verbal directions to the tangible pictures, since the stimuli were widely spaced. The subjects were successful in restricting exploration to the designated picture. As in Experiments $1-3$, the subjects were timed with a stopwatch, and no feedback was given.

\section{Results and Discussion}

The results of Experiment 3 are consistent with the idea that visual experience can influence picture identification

Table 7

Characteristics of the Blind Subjects, Including Age, Education, Cause, and Presence of Light Perception (LP) in Experiment 4

\begin{tabular}{|c|c|c|c|c|c|c|c|c|c|}
\hline \multicolumn{5}{|c|}{ Congenitally Blind } & \multicolumn{5}{|c|}{ Late Blind } \\
\hline Gender & Age & LP? & Cause & Education & Gender & Age & LP? & Cause & Education \\
\hline $\mathrm{F}$ & 18 & Yes & Trauma ( 3 months) & $\mathrm{SC}$ & M & 27 & No & Glaucoma (12) & MA \\
\hline$M$ & 27 & Yes & RLF & MA & M & 29 & No & Detached retina (13) & HS \\
\hline $\mathrm{F}$ & 28 & No & RLF & HS & M & 30 & No & $\begin{array}{l}\text { Glaucoma }(1-2) \\
\text { and optic nerve }\end{array}$ & $\mathrm{SC}$ \\
\hline$F$ & 28 & No & Born without eyes & $\mathrm{SC}$ & M & 34 & No & Retinoblastoma (2) & $\mathrm{SC}$ \\
\hline $\mathrm{F}$ & 35 & No & Optic nerve & $\mathrm{SC}$ & M & 35 & Yes & $\begin{array}{l}\text { Trauma, cataracts } \\
\text { and glaucoma (7) }\end{array}$ & $\mathrm{SC}$ \\
\hline $\mathrm{M}$ & 38 & Yes & RLF & HS & $\mathrm{F}$ & 36 & Yes & $\mathrm{RP}(21)$ & BA \\
\hline $\mathrm{F}$ & 41 & No & Glaucoma & $\mathrm{SC}$ & $\mathrm{M}$ & 47 & No & Glaucoma (8) & HS \\
\hline $\mathbf{M}$ & 51 & No & Born without eyes & MA & $\mathrm{M}$ & 47 & Yes & $\mathrm{RP}(42)$ & HS \\
\hline $\mathbf{F}$ & 55 & No & Born without eyes & HS & M & 55 & No & $\mathrm{RP}(40)$ & $\mathrm{HS}$ \\
\hline M & 56 & No & $\begin{array}{l}\text { Glaucoma and } \\
\text { cataracts ( } 3 \text { months) }\end{array}$ & HS & $\mathrm{F}$ & 57 & Yes & Diabetes (50) & HS \\
\hline
\end{tabular}

Note-Many blind subjects attended rehabilitation programs after finishing high school. Age at complete loss of vision is shown in parentheses. Mean age of congenitally blind subjects $=37.7$; mean age of late blind subjects $=39.7$; mean age of loss of vision of late blind subjects $=$ 19.65, $S D=17.9$. RP, retinitis pigmentosa; RLF, retrolental fibroplasia. HS, high school; SC, some college; BA, bachelor of arts degree; MA. master of arts degree. 
Table 8

Pereent Correct, Mean Identification Time (in Seconds), and Standard Deviation of Identification Time (in Seconds) as a Function of

Picture and Visual Experience in Experiment 4

\begin{tabular}{|c|c|c|c|c|c|c|c|c|c|}
\hline \multirow[b]{2}{*}{ Picture } & \multicolumn{3}{|c|}{ Congenitally Blind } & \multicolumn{3}{|c|}{ Late Blind } & \multicolumn{3}{|c|}{ Sighted } \\
\hline & $\begin{array}{l}\text { Percent } \\
\text { Correct }\end{array}$ & Time & $S D$ & $\begin{array}{l}\text { Percent } \\
\text { Correct }\end{array}$ & Time & $S D$ & $\begin{array}{l}\text { Percent } \\
\text { Correct }\end{array}$ & Time & $S D$ \\
\hline Chair & 50 & 55.9 & 86.2 & 100 & 7.9 & 6.6 & 100 & 30.3 & 21.4 \\
\hline Lamp & 0 & 56.1 & 54.8 & 80 & 24.2 & 25.0 & 40 & 54.0 & 35.8 \\
\hline Table & 50 & 29.3 & 43.2 & 90 & 15.6 & 14.2 & 70 & 22.9 & 8.7 \\
\hline Bicycle & 20 & 42.5 & 54.1 & 50 & 40.5 & 25.8 & 30 & 49.9 & 31.2 \\
\hline Car & 50 & 31.0 & 32.9 & 100 & 20.3 & 22.2 & 40 & 63.4 & 37.1 \\
\hline Truck & 50 & 43.9 & 53.3 & 80 & 24.1 & 27.4 & 30 & 47.6 & 25.7 \\
\hline Bowl & 0 & 74.4 & 54.2 & 50 & 33.3 & 24.1 & 50 & 32.2 & 18.3 \\
\hline Knife & 60 & 26.1 & 28.6 & 80 & 15.0 & 12.6 & 60 & 33.4 & 36.2 \\
\hline Spoon & 90 & 9.8 & 10.3 & 100 & 9.8 & 18.1 & 100 & 19.2 & 13.3 \\
\hline Ear & 10 & 42.7 & 42.8 & 50 & 41.0 & 41.1 & 50 & 33.6 & 22.8 \\
\hline Lips & 10 & 51.2 & 64.3 & 40 & 30.7 & 28.3 & 40 & 41.4 & 30.0 \\
\hline Nose & 10 & 54.7 & 48.0 & 30 & 48.3 & 35.2 & 50 & 47.1 & 29.5 \\
\hline Apple & 60 & 13.2 & 15.2 & 100 & 9.9 & 6.9 & 70 & 18.7 & 9.0 \\
\hline Banana & 100 & 7.5 & 5.9 & 90 & 7.3 & 4.4 & 100 & 19.5 & 13.3 \\
\hline Cherries & 0 & 38.1 & 30.8 & 20 & 36.9 & 42.7 & 20 & 46.8 & 42.3 \\
\hline
\end{tabular}

(see Tables 8 and 9). While the late blind ( $M=10.6$ correct, $S D=2.5$; mean percent correct $=70.7)$ and sighted subjects $(M=8.5$ correct, $S D=2.4$; mean percent correct $=56.7$ ) showed performance that was similar, the performance of both of these groups of subjects was similar to that of the sighted subjects in Experiments 1 and 2. These subjects were clearly able to benefit from categorical information. The congenitally blind subjects showed a much lower mean accuracy $(M=5.6$ correct, $S D=2.4$; mean percent correct $=37.3$ ). Their scores were only slightly higher than those of the sighted controls denied categorical information in Experiment 1. A one-way ANOVA on number correct showed a significant effect of visual experience $[F(2,27)=10.7, p<.001]$. A NewmanKeuls test on the means showed that the late blind and blindfolded sighted means were not significantly different, but both groups had higher scores than the congenitally blind participants $(p<.05)$. The accuracy data were analyzed using picture category as a within-groups variable and showed significant effects of visual status $[F(2,27)=$ $10.7, p<.001]$ and picture category $[F(4,108)=8.7, p<$ $.001]$, and the interaction was also significant $[F(8,108)=$ $2.2, p<.05]$. Analyses of simple effects of visual status showed that the three groups of subjects showed similar performance on the kitchen utensils and fruit, but differences appeared for the body parts, furniture, and vehicles. These differences are probably due, in part, to differential familiarity with the objects (e.g., vehicles; see Tables 8 and 9). In addition, the congenitally blind subjects had much lower performance on the representations of body parts, perhaps because the configurations were incomplete and appeared out of context. ${ }^{2}$

A second ANOVA was performed on RT and showed a nonsignificant effect of visual status $[F(2,27)=1.25$, $p>.05]$, a significant effect of picture category $[F(4,108)=8.3, p<.001]$, and a significant interaction effect $[F(8,108)=2.1, p<.05]$. Simple effects of pic- ture category were significant for all groups of subjects (all $p \mathrm{~s}<.01$ ). This reflects faster identification of some categories of pictures than of others for all of the three groups of subjects. However, the simple effect of visual status was significant only for furniture $(p<.05)$ and probably derived from much faster performance by the late blind subjects than by the congenitally blind or sighted subjects (see Table 9).

Visual experience clearly influenced the accuracy of tactual picture naming, since the sighted and late blind subjects performed better than did the congenitally blind participants. The late blind subjects performed better than the other subjects. Although the late blind did not show significantly higher accuracy than the sighted sub-

Table 9

Percent Correct, Mean Identification Time (in Seconds), and Standard Deviation as a Function of Category and $\checkmark$ isual Experience in Experiment 4

\begin{tabular}{|c|c|c|c|c|c|c|}
\hline \multirow[b]{2}{*}{ Category } & \multicolumn{2}{|c|}{$\begin{array}{c}\text { Congenitally } \\
\text { Blind }\end{array}$} & \multicolumn{2}{|c|}{ Late Blind } & \multicolumn{2}{|c|}{ Sighted } \\
\hline & $\begin{array}{l}\text { Percent } \\
\text { Correct }\end{array}$ & Time & $\begin{array}{l}\text { Percent } \\
\text { Correct }\end{array}$ & Time & $\begin{array}{l}\text { Percent } \\
\text { Correct }\end{array}$ & Time \\
\hline \multicolumn{7}{|l|}{ Furniture } \\
\hline$M$ & 33.3 & 47.1 & 90.0 & 15.9 & 70.0 & 35.7 \\
\hline$S D$ & 27.2 & 45.4 & 16.1 & 14.4 & 24.6 & 15.8 \\
\hline \multicolumn{7}{|l|}{ Vehicles } \\
\hline$M$ & 40.0 & 39.1 & 76.7 & 28.3 & 33.3 & 53.6 \\
\hline$S D$ & 41.0 & 43.1 & 22.5 & 20.4 & 27.2 & 27.4 \\
\hline \multicolumn{7}{|c|}{ Kitchen utensils } \\
\hline$M$ & 50.0 & 36.8 & 76.7 & 19.4 & 70.0 & 28.3 \\
\hline$S D$ & 23.6 & 24.6 & 22.5 & 11.8 & 24.6 & 14.8 \\
\hline \multicolumn{7}{|l|}{ Body parts } \\
\hline$M$ & 10.0 & 49.5 & 40.0 & 40.0 & 46.7 & 40.7 \\
\hline$S D$ & 22.5 & 48.3 & 46.6 & 27.8 & 45.0 & 19.1 \\
\hline \multicolumn{7}{|l|}{ Fruit } \\
\hline$M$ & 53.3 & 19.6 & 70.0 & 18.0 & 63.3 & 28.3 \\
\hline$S D$ & 17.2 & 14.3 & 18.9 & 17.0 & 24.6 & 16.9 \\
\hline
\end{tabular}

Note-There were three pictures in each category. 
jects did, there were some obvious performance differences between these two groups. The late blind subjects were much faster for some categories of pictures and probably traded off accuracy for speed. These data are consistent with prior reports of improved performance in the late blind (Heller, 1989a).

The significant interaction between visual status and picture category (on number correct) is important and should be noted $[F(8,108)=2.2, p<.05]$. The differences between categories and pictures clearly influenced the ease or difficulty of picture identification. Thus, the congenitally blind subjects actually had slightly higher mean scores on the vehicles than did the sighted individuals, and these depictions were the most detailed. On fruit, the groups were rather close in performance. Clearly, there were large differences as a function of experience: performance differed for the blind groups on the pictures of the furniture. The lamp is less familiar and less meaningful for the congenitally blind subjects. Unless those individuals are visited by sighted persons or have a canine companion, they are unlikely to use lamps very much. Furthermore, the pictures of body parts were problematic for the congenitally blind individuals. One reviewer pointed out that the picture of the nose would be easily confused with other body parts with a bend, and this was revealed in the responses of the subjects; many subjects called this an "elbow." In addition, blind people may be more likely to think of the lips as parted, and the drawing of the ear was confused with a number of other body parts.

\section{GENERAL DISCUSSION}

Picture identification was aided in Experiment 1 through the provision of prior categorical information. Experiment 2 showed that categorical information improved picture naming even when the superordinate category was presented after each picture but before the naming response. This result suggests that the effect of categorical information is likely to be on identification or naming, rather than on perception of the pattern per se. In addition, giving category names at the start of the experiment also aided picture naming. This is also consistent with a labeling interpretation of naming failures in the data. Experiment 3 showed that tactual picture recognition can be very accurate when subjects do not have any difficulty locating picture names in their mental lexicons. This was demonstrated by using a multiplechoice recognition task, in which the subjects were asked to search through 3 pictures for a target picture. Experiment 4 showed that visual experience had a significant impact on the accuracy of tactual picture naming, even when all subjects were given prior categorical information about the tangible pictures.

The results of the experiments, taken together, suggest that tactual picture recognition can be very good. Moreover, the data suggest that an important aspect of the difficulty in tactual picture naming may derive from prob- lems in locating picture names in semantic memory, in addition to any possible deficit in perceptual processing. This conclusion is suggested by the high level of performance in the multiple-choice task, where the subjects were given the name of a target picture and were told to locate that target item. The subjects in Experiment 3 were accurate and relatively fast in locating target pictures. Of course, the data of Experiment 3 do not allow one to completely distinguish the effects of naming and labeling from the influence of higher order categorical information. That is, subjects may understand the pattern in a tangible drawing but still not know what sort of object is represented or the name of that object. Clearly, the provision of categorical information could solve both problems for the perceiver. Furthermore, one cannot completely rule out the possibility that categorical information can help refine tactual search for features that may characterize a particular depiction (e.g., the point of a knife).

The results of the present experiments are relevant to a theoretical formulation by Lederman and Klatzky (e.g., Lederman et al., 1990). They proposed that touch is faced with difficulty when confronted with two-dimensional configurations, where sequential exploration imposes a burden on memory. Touch does very well when an individual explores common, familiar three-dimensional objects. They argued that the difference in performance between these two instances does not lie in our greater familiarity with three-dimensional objects and very little experience examining two-dimensional configurations. Rather, they suggested that touch requires the intervention of visual imagery when people examine twodimensional patterns, such as raised line drawings. Individuals do well when actively manipulating common objects, because they have access to information about the material properties of objects. Touch excels in the perception of such properties as texture, hardness, and the thermal nature of objects. Thus, visual recoding is not necessary when haptic coding will suffice, as for recognition of common objects.

This theoretical position suggests that visual imagery may operate in two different ways to influence performance in a picture-identification task. Visual imagery could facilitate access to naming and aid subjects in locating the labels of objects. Alternatively, visual imagery could aid perceptual processing as subjects try to determine the nature of the pattern. The results of the present experiments, while consistent with both of these possible mechanisms, suggest that visual imagery probably helps subjects locate the names of objects and involves semantic memory. Of course, it is also possible that visual imagery aids subjects as they try to decide the general nature of an object represented in a drawing. This interpretation is supported by the results of Experiments 1 and 2. Tactual picture-recognition performance can be good, especially when subjects do not have to scan memory and relate a perceived shape to an unspecified mental label. Participants are frequently able to describe the 
shape of something they feel, yet they are not always able to name the configuration. ${ }^{3}$

How are we to interpret the lower performance of the congenitally blind individuals in Experiment 4? This result was very different from that reported by Heller (1989a), who found that the congenitally blind subjects performed as well as the blindfolded sighted subjects did. Furthermore, the congenitally blind subjects in the earlier study (Heller, 1989a) were able to improve performance substantially after hearing the set of names that described the pictures. In Experiment 4, however, performance was lower overall for the congenitally blind subjects, despite prior categorical information.

One possibility is that the congenitally blind subjects do not have the capability of generating visual images, and these may be necessary for the perception of twodimensional patterns, such as tangible pictures. With this interpretation of the data, the imagery of the congenitally blind individual is not adequate for information pickup when examining raised line drawings. This is not the most convincing interpretation of the data, since congenitally blind people are able to interpret graphics (e.g., Heller \& Joyner, 1993; Heller \& Kennedy, 1990).

One might recall that the congenitally blind subjects showed higher levels of performance when the set of picture names was given prior to the second presentation of the pictures (Heller, 1989a). In the present study, the congenitally blind subjects did not show the same levels of performance as those individuals who had visual experience, and this may reflect the advantages of visual imagery for retention and higher cognitive stages of processing. It should be noted that some of the congenitally blind subjects in the earlier study (Heller, 1989a) repeatedly asked for repetition of the set of choice names. This suggests that subjects may have suffered a severe cognitive load as they attempted to feel the raised line pictures and identify them. The sighted or late blind subjects rarely made this sort of request. These observations are also consistent with the idea that memory demands represent an important part of the problem in tactual picture identification.

Visual imagery may help subjects in a picture identification task, but it is not necessary. This interpretation is likely, given the data of the four experiments. Support for this interpretation derives from the finding that the congenitally blind did not fail with all of the pictures (e.g., the banana and spoon). Recall that their performance was actually higher than that of sighted subjects for pictures of vehicles and was very close to that of the sighted subjects for pictures of fruit. Their mean overall performance was merely lower than that of the other subjects (see Tables 8 and 9). In addition, there were large individual differences in performance in this task. Some subjects did poorly. A few congenitally blind subjects, however, performed at a higher level than did some sighted individuals restricted to touch.

Moreover, visual experience and familiarity with pictures could also help provide sighted and late blind sub- jects with ready access to the nature or category of the object depicted. Many of the pictures in the present experiments were familiar and relatively easy for sighted subjects to visually label, since they were visually normed (Snodgrass \& Vanderwart, 1980). Thus, it is possible that this familiarity could help sighted and late blind subjects determine the subcategory of the drawn object. For example, subjects were told that some of the pictures were of furniture. Congenitally blind subjects were unlikely to think that this could include objects such as a lamp and were likely to call the lamp a "dresser" or a "chair." This interpretation of the data of Experiment 4 is consistent with the obtained interaction between picture category and visual experience.

There are other related interpretations of the effects of visual experience that should be considered. The crucial variable may not be a lack of visual experience, rather a lack of experience with pictures of any sort. The basic problem for the researcher is that increased visual experience can have a number of consequences for the perception of tangible graphics, including experience that may be qualitatively different from touch and specifically visual. Some visual imagery may not be readily available to haptics, such as when representing color or shading, but that was not a problem for the line drawings in the present experiments. The congenitally blind subjects have had very little or no familiarity with pictures, and many had no experience with tangible pictures of objects. Thus, poor performance could derive from minimal experience making the translation from a threedimensional world to a two-dimensional picture plane, and vice versa. This could explain the lower performance of the congenitally blind subjects with pictures such as the lamp and bowl. With this interpretation of the data, identification of tangible pictures is a skill that may reflect experience with pictures and practice. Thus, the congenitally blind subjects are not skilled or practiced in the production or interpretation of tangible pictures, and this contributed to their lower overall performance in the picture-identification task.

Attention and memory load can be especially acute problems for subjects given novel tactual tasks. Note that sighted subjects perform very poorly and slowly when they first attempt visual matching to tangible braille patterns, and they may take more than $5 \mathrm{sec}$ for identification of an individual character (see Heller, 1992). Skilled braille readers showed errorless reading of two-letter braille words, with a mean reading time of less than $2 \mathrm{sec}$ per word, but sighted subjects were very slow when reading braille words and had poor accuracy (Heller, 1993). Sighted subjects required about $50-60 \mathrm{sec}$ to read two-letter braille words, yet their mean accuracy was no better than $40 \%$ correct. Rate and memory load are also a problem for sighted subjects when one prints letters, words, or number sequences on the skin of the palm (Heller, 1980, 1987), yet it is possible that practice may reduce the rate and retention problems for the deaf-blind person (see Heller, 1986). It is an empirical question as 
to whether practice will prove beneficial for the perception of tangible graphics by congenitally blind people, and future research should be directed toward answering this question. The advantage of the late blind in the present and past research also suggests the importance of experience and skill for picture perception.

There may be differences between visual imagery and haptic imagery that could influence memory, coding, and perception. However, these differences might derive from differential familiarity with pictures, rather than specifically visual experience with pictures. Thus, sighted and late blind subjects may be better than congenitally blind subjects in generating mental pictorial images, owing to increased exposure to pictures and experience with their interpretation. It is difficult to know whether these images are specifically visual, and not spatial, or amodal two-dimensional pictorial representations. One blind person told the first author of this manuscript (M.A.H.) that she understood that sighted people only see "half of a tree, while blind people imagine the whole tree." She clearly meant that she knew that sighted people adopt a "point of view," but blind people tend to develop a unitary image of a three-dimensional object. This tendency to imagine objects as a whole may derive from haptic experience, such as when we wrap our appendages around objects (see Revesz, 1950). However, there is nothing about haptics that precludes a blind individual from taking a vantage point. Blind people are able to imagine a complex array from different vantage points, in a tactual analogue of the Piagetian perspective-taking task (Heller $\&$ Kennedy, 1990). Furthermore, blind participants reacted somewhat differently to specific pictures and picture categories in the present study. Many congenitally blind subjects, for example, noted that they had a problem with the bowl. None of them correctly identified that picture, and all of the congenitally blind subjects indicated they were confused by the line that was designed to represent depth (see Table 8). Further research is needed to clarify relevant mechanisms in the perception of tangible representations of depth by congenitally blind people.

\section{REFERENCES}

APPELLE, S. (1991). Haptic perception of form: Activity and stimulus attributes. In M. A. Heller \& W. Schiff (Eds.), The psychology of touch (pp. 169-188). Hillsdale, NJ: Erlbaum.

ApPelle, S., \& GravetTer, F. J. (1985). Effect of modality-specific experience on visual and haptic judgment of orientation. Perception, 14, 763-773.

Arditi, A., Holtzman, J. D., \& Kosslyn, S. M. (1988). Mental imagery and sensory experience in congenital blindness. Neuropsychologia, 26, I-12.

Cornoldi, C., Bertuccelli, B., Rocchi, P., \& Sbrana, B. (1993). Processing capacity limitations in pictorial and spatial representations in the totally congenitally blind. Cortex, 29, 675-689.

Cornoldi, C., CoRTesi, A., \& Preti, D. (1991). Individual differences in the capacity limitations of visuospatial short-term memory: Research on sighted and totally congenitally blind people. Memory \& Cognition, 19, 459-468.

Critchley, M. (1953). The parietal lobes. New York; Hafner.

DRETSKE, F. (1990). Seeing, believing, and knowing. In D. N. Osherson,
S. M. Kosslyn, \& J. M. Hollerbach (Eds.), Visual cognition and action (Vol. 2, pp. 129-148). Cambridge, MA: MIT Press.

Heller, M. A. (1980). Tactile retention: Reading with the skin. Perception \& Psychophysics, 27, 125-130.

HELLER, M. A. (1986). Central and peripheral influences on tactual reading. Perception \& Psychophysics, 39, 197-204.

HeLler, M. A. (1987). Improving the passive tactile digit span. Bulletin of the Psychonomic Society, 25, 257-258.

Heller, M. A. (1989a). Picture and pattern perception in the sighted and blind: The advantage of the late blind, Perception, 18, 379-389.

Heller, M. A. (1989b). Texture perception in sighted and blind observers. Perception \& Psychophysics, 45, 49-54.

Heller, M. A. (1991). Haptic perception in blind people. In M. A. Heller \& W. Schiff (Eds.), The psychology of touch (pp. 239-261). Hillsdale, NJ: Erlbaum.

Heller, M. A. (1992). The effect of orientation on tactual braille recognition: Optimal touching positions. Perception \& Psychophysics, 51, 549-556.

HELLER, M. A. (1993). Influence of visual guidance on braille recognition: Low lighting also helps touch. Perception \& Psychophysics, 54, 675-681.

Heller, M. A., \& Joyner, T. D. (1993). Mechanisms in the haptic horizontal-vertical illusion: Evidence from sighted and blind subjects. Perception \& Psychophysics, 53, 422-428.

Heller, M. A., \& KenNedy, J. M. (1990). Perspective taking, pictures, and the blind. Perception \& Psychophysics, 48, 459-466.

Heller, M. A., Kennedy, J. M., \& Joyner, T. D. (1995). Production and interpretation of pictures of houses by blind people. Perception, 24, 1049-1058.

Heller, M. A., Nesbitt, K. D., \& Scrofano, D. K. (1991). Influence of writing style and categorical information on identification of tactile numerals and letters. Bulletin of the Psychonomic Society, 29, 365-367.

HELleR, M. A., \& SCHIFF, W. (1991). Conclusions: The future of touch. In M. A. Heller \& W. Schiff (Eds.), The psychology of touch (pp. 327. 337). Hillsdale, NJ: Erlbaum.

KaTZ, D. (1989). The world of touch (L. E. Krueger, Trans.). Hillsdale, NJ: Erlbaum.

Kennedy, J. M. (1993). Drawing and the blind. New Haven: Yale University Press.

Klatzky, R. L., \& Lederman, S. J. (1993). Toward a computational model of constraint-driven exploration and haptic object identification. Perception, 22, 597-621.

Lederman, S. J., Klatzky, R. L., Chataway, C., \& Summers, C. D. (1990). Visual mediation and the haptic recognition of twodimensional pictures of common objects. Perception \& Psychophysics, 47, 54-64.

Lehtinen-Railo, S., \& Juurmaa, J. (1994). Effect of visual experience on locational judgments after perspective change in small-scale space. Scandinavian Journal of Psychology, 35, 175-183.

LoOMIS, J. M. (1990). A model of character recognition and legibility. Journal of Experimental Psychology: Human Perception \& Performance, 16, 106-120.

Loomis, J. M., KLATZKy, R. L., \& Lederman, S. J. (1991). Similarity of tactual and visual picture recognition with limited field of view. Perception, 20, 167-177.

Merry, R. V., \& MerRy, F. K. (1933). The tactual recognition of embossed pictures by blind children. Journal of Applied Psychology, 17, 148-163.

MillaR, S. (1975). Visual experience or translation rules? Drawing the human figure by blind and sighted children. Perception, 4, 363371.

MiLlaR, S. (1991). A reverse lag in the recognition and production of tactual drawings: Theoretical implications for haptic coding. In M. A. Heller \& W. Schiff (Eds.), The psychology of touch (pp. 301325). Hillsdale, $\mathrm{NJ}$ : Erlbaum.

Revesz, G. (1950). The psychology and art of the blind. London: Longmans Green.

SNOdgrass, J. G., \& VANDERwart, M. (1980). A standardized set of 260 pictures: Norms for name agreement, image agreement, famil- 
iarity, and visual complexity. Journal of Experimental Psychology: Human Learning \& Memory, 6, 174-215.

Winer, B. J., Brown, D. R., \& Michels, K. M. (1991). Statistical principles in experimental design. New York: McGraw-Hill.

\section{NOTES}

1. The data of this experiment were reanalyzed, but considered the responses "grapes" and "apples" as correct for the picture of the cherries and counted the response "motorcycle" as correct for the picture of the bicycle. The results of the ANOVA were similar to that of the main analysis.

2. The accuracy data of this experiment were reanalyzed, but considered the responses "grapes" and "apples" as correct for the picture of the cherries. However, the response of "motorcycle" was not scored as correct for the picture of the bicycle, since none of the sighted subjects used this name when visually identifying the stimuli after the experiment. "Grapes" and "apples" were sometimes obtained as visual responses. Use of this looser method of scoring yielded higher mean accuracy for the late blind subjects $(M=11.4$ correct, $S D=2.41$; percent correct $=76)$ than for the sighted subjects $(M=9.1$ correct, $S D=2.2$; percent correct $=60.7)$ or the congenitally blind participants $(M=6.2$ correct, $S D=2.3$, percent correct $=41.3)$. A one-way ANOVA on number correct showed that the effect of visual status was significant $[F(2,27)=12.8, p<.001]$. A Newman-Keuls test on the means for the loose method of scoring number correct showed that all of the means were significantly different $(p<.05)$. A further analysis considered picture category as a variable and yielded a significant interaction between visual status and type of picture $[F(8,108)=2.02$, $p=.05]$. This interaction derived from the congenitally blind subjects showing especially low performance on the pictures of body parts. Note that the late blind subjects had very high scores for the fruit, vehicles, and furniture categories. These analyses suggest that the late blind subjects may have been aided by early visual experience, along with the advantage of increased perceptual skills derived from tactual experience.

3 . The reviewers correctly pointed out that it is difficult to isolate access to semantic memory from other factors, such as problems in perceptual uptake. One reviewer noted that many pictures, especially when perceived by touch with the loss of higher spatial frequencies, are ambiguous. If shape information were lacking or poor, and information about shape were ambiguous, one might generate a large number of possible names when confronted by a tangible picture. These names might reflect stimuli with similar shapes. Naming the depicted category or shape removes the problem of searching through a large number of names, reduces the ambiguity, and improves the subject's chances of answering correctly. With this interpretation of the data, there are few problems with naming or accessing semantic information. It is difficult, of course, to discount this sort of interpretation of the data. One problem with this interpretation is that it assumes that drawings are perfect replicas of reality and that vision never makes errors. Unfortunately, one can make the same sort of argument about visual line drawings and point toward the visual naming errors that some subjects make (see Snodgrass \& Vanderwart, 1980). While these visual errors are less frequent than those usually found in touch, they are similar in kind.

(Manuscript received November 15, 1994; revision accepted for publication July 31,1995 .) 